\title{
O USO DE MATERIAIS CONCRETOS E HISTÓRIAS EM QUADRINHOS COMO METODOLOGIA DE ENSINO
}

\author{
Queila Batista Muniz de Azevedo ${ }^{1}$ \\ Romário Freire Santos ${ }^{2}$
}

\section{RESUMO}

O presente trabalho foi desenvolvido com base em experiências vivenciadas na disciplina de Matemática, em uma turma do $8^{\circ}$ ano do Ensino Fundamental II, durante o Estágio Supervisionado III, na Escola Estadual do Município de Caetité/BA, no ano de 2015. Buscase retratar as atividades desenvolvidas com materiais manipuláveis e histórias em quadrinhos, elaboradas no Software HagáQuê, que favorecem a contextualização dos conteúdos envolvendo ângulos e plano cartesiano com o cotidiano dos alunos. As metodologias adotadas permitiram aos alunos uma aproximação dos aspectos teóricos e práticos dos conteúdos e despertaram motivação e interesse nestes discentes. Aos estagiários, a experiência acarretou a discussão do contexto escolar e a compreensão da importância de analisar sucintamente a prática pedagógica no decorrer das aulas, bem como, compreender a necessidade de se manter teoria e prática sempre juntas e refletir as mudanças correntes que envolvem o âmbito escolar.

Palavras chave: Materiais Manipuláveis; Histórias em Quadrinhos; Prática; Teoria; Aprendizagem.

\footnotetext{
${ }^{1}$ Mestranda em Ciências da Educação - Facultad Interamericana de Ciências Sociales - FICS Assunção - Paraguai.

Contato: E-mail: queilabm.yen@ hotmail.com

${ }^{2}$ Mestrando em Matemática - PROFMAT (IMPA) - Universidade Estadual do Sudoeste da Bahia.

Contato: E-mail : $\underline{\text { rfsantos2012.1@gmail.com }}$
} 


\section{INTRODUÇÃO}

O presente trabalho se propõe discutir o uso de materiais manipuláveis e histórias em quadrinhos como estratégia de ensino no decorrer das aulas de estágio, tendo como principal objetivo, amenizar as dificuldades encontradas pelos alunos na aprendizagem dos conceitos de ângulos e plano cartesiano. Além disso, discute também as contribuições dessas atividades para a formação do estagiário/professor, considerando que este é o primeiro contato do estagiário com o contexto da sala de aula, é quando se dispõe a assumir o lugar do professor.

Pimenta (2012) e Fazenda (1991) consideram que o encontro com o futuro local de atuação é o momento em que o licenciando tem a oportunidade de correlacionar teoria e prática; de constatar a partir da aplicação da teoria e dos conhecimentos construídos no decorrer de sua graduação que o ensino deve ser embasado na realidade da escola; e perceber que o conhecimento do campo profissional se constrói no contato com a sala de aula, é quando tem a oportunidade de rever conceitos imprescindíveis ao ato de ensinar.

As experiências vivenciadas no decorrer do estágio devem possibilitar ao estagiário uma reflexão crítica sobre suas próprias ações, contribuindo para a reelaboração de conceitos já existentes, para a elaboração de novos conceitos e desenvolvimento das habilidades necessárias ao futuro professor.

Nos momentos de reflexões, os estagiários têm a oportunidade de perceber que, no período de regência, ocorrem interações entre sujeitos de diferentes contextos sócio culturais, por isso, suas ações devem ser pensadas com foco na realidade dos alunos, para que estes tenham a oportunidade de vivenciar, na sala de aula, momentos de aprendizagens que tenham coerência com a sua realidade.

Quando o foco do estágio está na ação e na teoria que aproxima o futuro professor da realidade escolar e dos aspectos sociais que envolvem a escola, a prática desenvolvida no decorrer do estágio pode trazer contribuições para os alunos, para o estagiário e para o processo de ensino aprendizagem, e torna ainda mais importante quando se sabe que trará alguns benefícios à comunidade (BIANCHI, 2001). O autor ainda afirma que é a 
oportunidade do estagiário aplicar e rever metodologias, promover a reflexão sobre a realidade e idealizar a escola de forma mais concreta, mostrando que tem competência para lecionar.

\footnotetext{
Compete ao aluno estar atento, demonstrar seu conhecimento pela teoria aprendida, realizar seu trabalho com dignidade procurando, dentro da sua área de atuação, demonstrar que tem competência, simplicidade, humildade e firmeza, lembrando-se que ser humilde é saber ouvir para aprender, ser simples é ter conceitos claros e saber demonstrá-los de maneira cordial (BIANCHI, 2001, p. 16 e 17).
}

Cabe ao estagiário ter a consciência de que deve ser crítico e investigativo perante os conteúdos, a realidade escolar e a sociedade, assim como, em relação a sua prática em sala de aula, o que pode proporcionar aprendizagem e desenvolvimento para o aluno e para o futuro profissional.

O estagiário deve conhecer o ambiente escolar, as possíveis metodologias e/ou métodos de ensino adotados pelos professores, os aspectos sociais que envolvem a instituição de ensino onde vai realizar o estágio, para ter condições de idealizar as atividades que vai traçar para a sua proposta de estagio, atividades estas que permitam a reflexão sobre a teoria/prática e admitam a análise da realidade social que envolve o contexto educacional (PIMENTA, 2012).

Abordaremos a seguir algumas ideias referentes à relação Prática/teoria/prática, discutidas previamente para o planejamento e nos momentos de reflexões sobre as práticas desenvolvidas no decorrer do estágio. Iniciaremos expondo as concepções de alguns autores, em seguida, apresentaremos duas das atividades propostas para o período de regência e a análise das ações ligadas às estratégias metodológicas desenvolvidas em sala de aula.

\section{O ESTÁGIO}

O Estágio Supervisionado na formação inicial do professor tem sido destaque nos estudos que apontam para suas dificuldades e seu potencial, proporcionando mudanças na vida desses profissionais. O estágio, segundo Pimenta e Lima (2004), precisa ser considerando como o eixo central da formação inicial do professor, é no decorrer dele que o 
discente entra em contato com o seu futuro espaço de trabalho, podendo conhecer os aspectos relacionados à formação da construção da identidade e os saberes do dia a dia.

Os diferentes componentes curriculares do curso de Licenciatura devem proporcionar a participação dos estagiários no contexto da sala de aula no decorrer do estágio, para que possam colocar os conhecimentos teóricos em prática. É preciso que o estagiário aprenda a criar condições que favoreçam a (re)construção do seu conhecimento a partir da observação e identificação dos problemas, para que tenha domínio na interpretação, análise e construção de caminhos perante os diferentes desafios presentes nas situações existentes na realidade do contexto escolar.

O Componente Curricular Estágio Supervisionado deve fornecer base para o discente em relação ao apreender a realidade, para que saiba como, quando e onde agir, além de saber distinguir, em cada parte, a essência do todo, que pode ter interpretações diversas aos olhares de outros indivíduos (PIMENTA, 2012), assim como "levar os alunos a uma análise das realidades sobre as quais atuarão, e também como fonte de experiências concretas para as discussões sobre as questões de ensino e procedimentos metodológicos" (PIMENTA, 2012, p.161).

Pimenta (2012) menciona que o Estágio Supervisionado possibilita, aos futuros docentes, a observação e reflexão sobre a realidade escolar vigente, servindo como um embasamento para a construção de teorias que, após novas reflexões e prática, ficam sujeitas a possíveis transformações decorrentes da sua relação com a realidade.

\section{PRÁTICA-TEORIA-PRÁTICA}

Para maior entendimento da relação prática-teoria-prática e a função do estágio perante esse sistema de relacionamento, e até em termos de educação e desenvolvimento do homem, é necessário entender que as atividades docentes desenvolvidas no decorrer do estágio são práxis e que a oposição entre teoria e prática implica negar a transição da atividade teórica para a atividade prática. Isso significa negar a teoria, da mesma forma, uma prática sem teoria não passa de senso comum (PIMENTA, 2012). Neste sentido Pimenta e 
Lima (2012) asseguram que ambas trilham o mesmo caminho, pois é a teoria que explica e valoriza a prática, e esta dá novo sentido para a teoria.

Pimenta e Lima (2012, p.45) asseguram que:

O estágio, ao contrário do que se propugnava, não é atividade prática, mas teórica, instrumentalizadora das práxis docentes, entendida esta como atividade de transformação da realidade. Nesse sentido, o estágio curricular é atividade teórica de conhecimento, fundamentação, diálogo e intervenção na realidade, esta, sim, objeto da práxis.

Para a autora, teoria não pode ser considerada como "um conjunto de regras, normas e conhecimentos sistematizados aplicáveis a qualquer contexto" (PIMENTA, 2012, p.78), mas que deve ser "formulada e utilizada a partir das necessidades concretas da realidade educacional, à qual busca responder através da orientação das linhas de ação" (PIMENTA, 2012, p.78). Assim, a Universidade deve mediar e contribuir para que os futuros docentes sejam profissionais críticos e reflexivos perante a realidade, capazes de aproximar-se das novas teorias e, consequentemente, aprimorar suas ações (FAZENDA, 1991).

O educador, ao observar criticamente modelos de regência existentes, com intenção de provocar mudanças em ações posteriores, acaba promovendo prática/teoria/prática, sendo esta uma maneira de relacionar teoria e prática. Como descrevem Candau e Lelis, "as formas de conceber a relação entre teoria e prática são certamente muitas. No entanto, acreditamos poder agrupá-las, fundamentalmente, em dois esquemas: a visão dicotômica e a visão de unidade" (CANDAU E LELIS 2014, p. 60).

Ainda de acordo com as autoras, na visão dicotômica, teoria e prática são dissociadas, mantém de maneira crucial a autonomia entre si, cada uma com suas especificidades, cabendo “aos 'teóricos' pensar, elaborar, refletir. Planejar, e aos 'práticos', executar, agir, fazer" (GANDAU e LELIS, 2014, p. 60).

$\mathrm{Na}$ visão de unidade, teoria e prática são elementos que, apesar de terem e manterem identidades próprias, são indissolúveis e recíprocos, sendo uma visão com grande valor na formação do educador ao envolver ações concretas, análise e reflexão sobre as ações e novamente a prática. O que corrobora com as ideias de Piconez $(1991, \mathrm{p} .16)$ ao relatar que "O contexto relacional entre prática-teoria-prática apresenta importante significado na formação do professor, pois orienta a transformação do sentido da formação do conceito de unidade, ou seja, da teoria e prática relacionadas e não justapostas ou dissociadas". 
Desse modo, o professor ou o estagiário deve buscar estratégias de ensino que auxiliem no processo ensino/aprendizagem, com aspectos mais dinâmicos, como as histórias em quadrinhos elaboradas no software HagáQuê e as atividades com dobraduras e cabide de madeira. Assim, pode haver uma aproximação das aulas aos recursos tecnológicos e manipuláveis, tendência que tem evoluído muito nas últimas décadas e que pode tornar o ensino mais atrativo para os alunos.

$\mathrm{Na}$ próxima sessão apresentaremos o relato das atividades propostas com objetos manipuláveis e histórias em quadrinhos.

\section{A EXPERIÊNCIA}

As atividades que serão mostradas foram desenvolvidas em uma turma do $8^{\circ}$ ano do Ensino Fundamental, de uma Escola Estadual do Município de Caetité/Ba em 2015. Na etapa de observação do Estágio Supervisionado III, em um período de 6 aulas (50 minutos cada), foi traçado o perfil dessa turma, composta por 35 alunos, porém com frequência regular de 34 alunos.

Durante o período de observação, foi notado que os alunos promoviam conversas paralelas, distraíam-se no decorrer da aula, não demonstravam interesse pelas atividades desenvolvidas pelo professor regente, assim como, alguns ficavam entrando e saindo na sala durante a aula. Foi percebido que somente uma minoria realizava as atividades extraclasses e, de modo geral, a turma apresentava baixo rendimento nas atividades avaliativas.

De modo análogo, foi observado que as estratégias metodológicas da regente centravam na exposição de conteúdos e na resolução de exercícios, ambos do livro didático e expostos na lousa.

O perfil da turma nos permitiu conjecturar que os estudantes não se sentiam atraídos pela aula, apresentavam dificuldades para realizar as atividades propostas, estado de desmotivação para estudar e certa aversão às aulas. Essas conjecturas levam à ideia de que a Matemática pode ser concebida pelos alunos como um "bicho de sete cabeças" (SOUSA, 2010, p.1), o que pode comprometer a aprendizagem. 
Após reflexão sobre o perfil da turma e sobre a prática da professora regente, foram propostas, como estratégia de ensino para a regência, terceira etapa do Estágio Supervisionado, atividades associadas ao uso de materiais concretos e Softwares Matemáticos, considerando que esses recursos didáticos podem facilitar o processo ensino aprendizagem e permitir ao estagiário e aos alunos uma visita ao contexto sócio cultural dos sujeitos. Além disso, por se tratar de algo novo, pode ser uma estratégia eficiente. Especificamente, no caso aqui descrito, essa estratégia veio despertar o interesse e a participação mais ativa da turma nas aulas, era visível a sua motivação, estava sempre atenta às explicações e fazendo questionamentos, ou seja, as atividades induziam à investigação.

No entanto, no período de observação e durante a regência, foi percebido que a escola não dispõe de alguns recursos necessários para realização das aulas, como laboratório de informática com computadores em quantidade suficiente para a turma e equipados com programas que podem auxiliar no processo de ensino aprendizagem. E isso limitou o uso de alguns recursos necessários para o desenvolvimento da metodologia proposta.

Nas aulas sobre ângulos, foi usado o cabide de madeira e dobraduras em folhas de papel, com o objetivo de estudar propriedades relativas (formação do ângulo por duas retas concorrentes, feixe de retas paralelas e uma transversal, ângulos opostos pelo vértice, classificação) a partir da sua visualização. Isso permitiu que os alunos demonstrassem seus conhecimentos prévios a respeito do conteúdo e percebessem a presença do assunto visto em sala de aula no seu dia-a-dia.

Assim, durante 6 aulas, foi debatido em sala com os alunos a respeito dos ângulos formados pelo cabide e pelas dobraduras em folhas de papel. Eles puderam questionar e investigar diversas situações de posicionamento dos ângulos, inclusive com questionamentos de alguns ângulos visualizados à medida que se dava a exploração dos cabides. Na sequência, os alunos promoveram a resolução de atividades com o referido conteúdo, de maneira que fosse possível debater com os colegas e com o professor e verificar exemplos diferentes dos estudados com os materiais utilizados. Em aulas posteriores, foi realizada uma atividade avaliativa (individual), sendo necessária a interpretação e descrição de alguns conceitos sobre ângulos.

Ao analisar as atividades individuais, foi possível constatar que a utilização dos materiais concretos (cabide de madeira e dobraduras em folhas de papel) durante a explicação 
de ângulos, possibilitou a visualização e exploração de situações do cotidiano para explicação dos conceitos matemáticos, o que pode tornar o conteúdo visto em sala de aula ainda mais significante para o aluno. E como descreve Sousa (2010), os objetos concretos possibilitam a aprendizagem de outros conceitos, além daqueles imaginados pelo professor.

Após realização das atividades com materiais concretos, foi necessário verificar a viabilidade de um planejamento análogo para o conteúdo referente a Plano Cartesiano, de maneira que fosse possível abstrair da realidade e dos conhecimentos anteriores do aluno, informações que pudessem contribuir para a compreensão de novas informações.

Assim, foram planejadas atividades com o uso de histórias em quadrinhos para explicação do conteúdo Plano Cartesiano, utilizando como auxílio durante a elaboração das histórias, um Software livre e gratuito, o HagaQuê. Este Software foi criado por pesquisadores da Unicamp (Universidade Estadual de Campinas) e é usado para a criação de histórias em quadrinhos, que podem ser ilustradas com imagens disponibilizadas por ele mesmo ou anexadas de outro meio. Dessa forma foi possível promover a contextualização a partir das histórias criadas, assim como propiciar a visualização da abordagem histórica do conteúdo através do lúdico das histórias em quadrinhos.

O objetivo foi explicar o conteúdo (Plano Cartesiano) a partir de algumas aplicações desde tempos remotos, como meio de localização, e também deixar a aula mais divertida. As atividades foram desenvolvidas em seis aulas e ocorreram por meio da leitura das histórias em quadrinhos pelos alunos, com questionamentos e debates sobre propriedades relativas. $\mathrm{O}$ uso das histórias em quadrinhos permitiu a contextualização, com abordagem de alguns exemplos da realidade do aluno em que se evidencia a aplicação do conteúdo visto em sala de aula.

$\mathrm{Na}$ realização das atividades, foi possível promover a interdisciplinaridade entre a matemática e a aplicação de alguns conceitos geográficos, bem como destacar o incentivo à leitura. Na figura I, no primeiro quadrinho, há uma associação do plano cartesiano com alguns elementos da realidade e, na segunda parte, há um conceito de posicionamento (geográfico) que é abordado pela história em quadrinhos utilizada para explicação do conteúdo. 

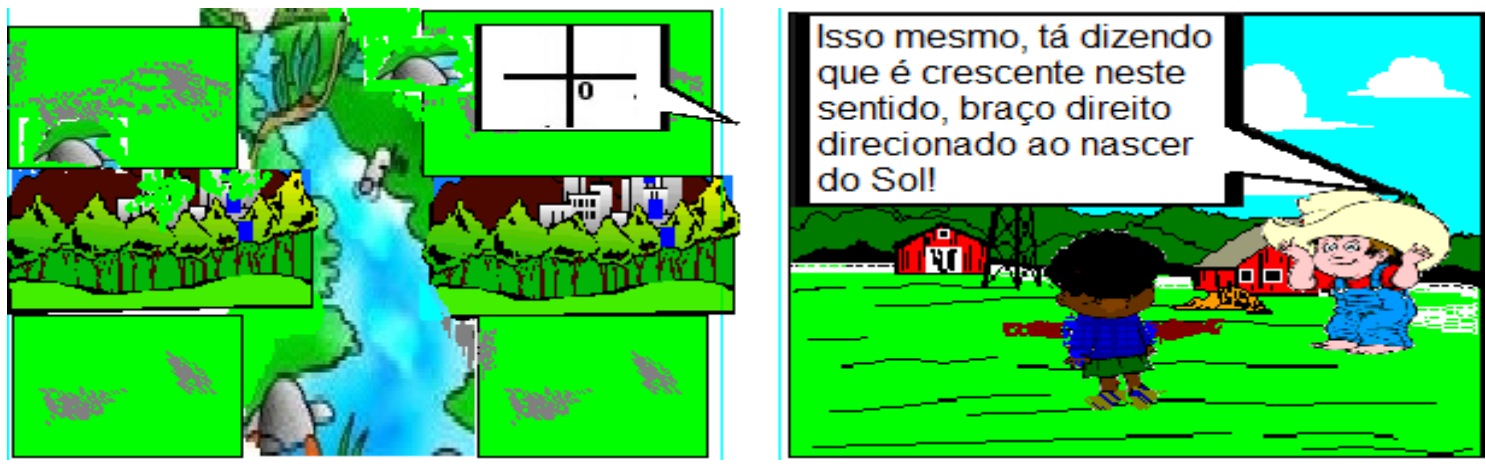

Figura I - Parte da História em Quadrinhos (Um Tesouro em Minha Terra) que fica evidenciado o plano cartesiano e é abordado sobre os pontos cardeais.

Na sequência, os alunos responderam exercícios referentes ao conteúdo e, em outras aulas, houve a aplicação da prova, que foi respondida individualmente pelos estudantes. Porém, não foram utilizadas histórias em quadrinhos nessas atividades propostas (exercícios e prova), pois a intenção era usar as histórias em quadrinhos apenas na metodologia adotada para explicação do conteúdo. Durante os exercícios, foram abordadas, principalmente, questões problemas.

Os alunos não tiveram a oportunidade de usar o Software utilizado para criação das histórias em quadrinhos, o HagaQuê, pois a escola não tem computadores suficientes para todos, assim como não tem o referido software instalado nos computadores acessíveis. Essa carência na infraestrutura da escola comprometeu o objetivo das atividades, pois os estudantes não tiveram a oportunidade de conhecer o referido software, verificar seus artifícios, criar suas próprias histórias em quadrinhos, dentre outros.

Ao analisar as resoluções das atividades e das provas desenvolvidas pelos alunos, foi possível notar uma abordagem dos conceitos matemáticos envolvidos no decorrer das explicações, principalmente, as propriedades relativas ao conteúdo Plano Cartesiano. Foi percebido que os alunos sentiram mais confiança em, ao menos, tentar responder as questões, o que pode ter sido pela maneira como tiveram acesso ao conteúdo, a partir das histórias em quadrinhos. Sendo assim, todas as resoluções foram analisadas e avaliadas, independentemente da resposta final, e no geral, os alunos tiveram um bom rendimento. 


\section{ALGUMAS CONSIDERAÇÕES}

No decorrer das atividades desenvolvidas com materiais manipuláveis e com histórias em quadrinhos, foi possível constatar que, com a aproximação das estratégias de ensino ao contexto sócio cultural dos sujeitos envolvidos no processo de ensino aprendizagem, os conteúdos discutidos em sala de aula foram bem compreendidos, assimilados e significantes para o aluno. As práticas adotadas interferiram diretamente no processo ensino aprendizagem.

Constamos também que, no decorrer das aulas, os alunos tiveram mais atenção e interagiram com o estagiário e com os colegas, apresentando melhores resultados nos exercícios resolvidos. Segundo Sousa (2010) o fato de relacionar os conteúdos com algo que faz parte do universo dos alunos pode deixá-los mais seguros e motivados, e isso permite que questionem, façam conjecturas e indagações.

Verificamos que, além de permitir a contextualização e a interdisciplinaridade dos conteúdos, as atividades desenvolvidas com o Software e com os materiais manipuláveis permitiram e induziram os alunos a participar mais das aulas. Assim, essas estratégias contribuíram positivamente para o desenvolvimento das atividades planejadas a partir do conhecimento da turma em questão.

Diante da experiência aqui descrita, reafirmamos a importância da relação de prática/teoria/prática no processo de ensino e aprendizagem e a necessidade de o professor estar sempre adequando as suas práticas ao contexto dos alunos, aos seus conhecimentos e vivências. As metodologias com o uso de histórias em quadrinhos e materiais concretos deram aos alunos a oportunidade de estudar determinados conteúdos, a partir do que já conheciam. Isso, como bem afirma Souza (2010) é partir de algo que já era real para eles e assim chegar ao concreto. Estas e outras possíveis metodologias é que fazem tanto o ensinar como o aprender ganhar sentido e legitimidade. 


\section{REFERÊNCIAS}

BIANCHI, A. C. M. Manual de Orientação Estágio Supervisionado. 2001. Pioneira Thomson Learning.

CANDAU, V. M. Rumo A Uma Nova Didática, 24 ed. - Petrópolis, RJ : Vozes, 2014.

FAZENDA, I. C. A.O Papel do Estágio nos Cursos de Formação de Professores. In STELA C. B. PICONEZ prática de Ensino e o Estágio Supervisionado. Bertholo Piconez (coord.).- Campinas, SP: Papirus, 1991. (Coleção Magistério: Formação e trabalho pedagógico).

PIMENTA, S. G. O Estágio na Formação de Professores: Unidade Teoria e Prática? - 11. Ed. - São Paulo: Cortez,2012.

PIMENTA, S. G. Estágio e Docência / Selma Garrido Pimenta, Maria Socorro Lucema Lima; revisão técnica Jpsé Cerchi Fusari, - 7. Ed - São Paulo: Cortez, 2012. - (Coleção docência em formação. - Série saberes pedagógicos).

SOUSA, G. C. ; OLIVEIRA, J. D. S. O Uso de Materiais Manipuláveis e Jogos no Ensino de Matemática. X Encontro Nacional de Educação Matemática. Salvador-BA, 2010. 